Cahiers $d u$ MONDE RUSSE

\section{Cahiers du monde russe}

Russie - Empire russe - Union soviétique et États indépendants

$51 / 4 \mid 2010$

Sciences humaines et sociales en Russie à l'Âge d'argent

\title{
William Nickell, The Death of Tolstoy
}

\section{Michel Aucouturier}

\section{(2) OpenEdition}

Journals

Édition électronique

URL : https://journals.openedition.org/monderusse/7369

DOI : 10.4000/monderusse.7369

ISSN : $1777-5388$

Éditeur

Éditions de l'EHESS

Édition imprimée

Date de publication : 25 novembre 2010

Pagination : 682-683

ISBN : 978-2-7132-2316-7

ISSN : $1252-6576$

Référence électronique

Michel Aucouturier, "William Nickell, The Death of Tolstoy », Cahiers du monde russe [En ligne], 51/4 I 2010, mis en ligne le 09 décembre 2011, consulté le 03 septembre 2022. URL : http://

journals.openedition.org/monderusse/7369; DOI : https://doi.org/10.4000/monderusse.7369

Ce document a été généré automatiquement le 3 septembre 2022

Tous droits réservés 


\title{
William Nickell, The Death of Tolstoy
}

\author{
Michel Aucouturier
}

\section{RÉFÉRENCE}

William NICKELL, The Death of Tolstoy. Russia on the Eve, Astapovo Station, 1910.

Ithaca - Londres : Cornell University Press, 2010, 209 p.

1 Peu d'événements ont suscité une aussi abondante littérature que la mort de Tolstoj. Projetée au premier plan de l'actualité par la fuite sensationnelle qui, quelques jours plus tôt, avait braqué sur l'écrivain les projecteurs de la presse, cette mort en recevait son éclairage de légende.

2 C'est cette immense littérature, plus que l'événement lui-même (rapporté dans ses moindres détails dans d'innombrables biographies et déjà minutieusement étudiép $)^{1}$, qui fait l'objet de l'étude de William Nickell : l'auteur s'attache à reconstituer l'élaboration, par « cet héritier de la tradition orale que sont les médias modernes », de cette véritable légende, ou, selon son expression, de ce "récit épique moderne " ("a modern epic») qu'est le récit de sa mort.

3 L'immense matériau documentaire (en partie réuni dans un recueil de documents publié à Moscou en $1929^{2}$, en partie conservé . ous forme de coupures de presse dans les archives du musée Tolstoj de Moscou) qu'il a réuni et très méticuleusement analysé - souvenirs de proches et de témoins, documents policiers, correspondance des autorités religieuses, articles de la presse quotidienne et commentaires des revues - lui permet d'isoler successivement, comme éléments constitutifs de cette légende, quatre grands enjeux.

Le premier est l'enjeu familial : la « fuite » de l'écrivain transforme en objet de discussion publique la crise familiale qui couve depuis de longues années derrière la façade bucolique de Jasnaja Poljana, où Sofia Tolstaja tente de protéger ses droits d'épouse et ceux de sa famille face aux prétentions des «tolstoïens» et de leur grand maître Čertkov. Vient ensuite l'enjeu religieux : la condamnation de Tolstoj par le saint-synode, 
en septembre 1901, conduit l'Église russe à chercher dans sa « fuite » un geste de repentir, et la place, à la veille et au lendemain de sa mort, devant un dilemme insoluble : soit se déjuger, soit se désolidariser d'un deuil national. L'enjeu médiatique est omniprésent : en cherchant à répondre à l'attente du public, la grande presse s'enferme elle aussi dans un dilemme puisqu'elle contribue à la fois à la désacralisation du personnage et à l'élaboration de la légende qui le sacralise. Vient enfin l'enjeu politique, sans doute le plus important, et qui se confond en fin de compte avec l'enjeu religieux. En restant en dehors du deuil populaire spontané suscité par la mort d'un écrivain dont l'œuvre est en partie interdite et dont les critiques violentes de l'action gouvernementale (notamment sur la peine de mort) ont fait de lui un grand « dissident », l'État, comme l'Église, laisse se développer en dehors de lui, et bientôt contre lui, un consensus national dont Tolstoj est l'incarnation; ses funérailles offriront le modèle d'une cérémonie laïque, organisée selon un rituel quasi religieux, mais en dehors de l'Église et de l'État, contribuant ainsi à développer dans l'intelligentsia russe un terrain propice à la révolution.

Dans un dernier chapitre, plus ambitieux et, nécessairement, plus contestable, l'auteur s'efforce d'élargir son sujet en situant cette légende dans le contexte européen de l'année 1910, décrite à partir de certains témoignages comme une année de crise générale de la civilisation, dont l'un des symptômes est une épidémie de suicides spectaculaires, perçus comme des tentatives de donner à la mort le caractère d'une conclusion significative de la vie. L'étude de W. Nickell s'achève sur les tentatives contemporaines de rattacher la «légende de Tolstoj » à cette crise, et sur la résistance que celle-ci y oppose.

\section{NOTES}

1. Cf. Boris Mejlah, Uhod i smert' Tolstogo [Le départ et la mort de Tolstoj], M. - L., 1960.

2. V. Nevskij éd., Smert' Tolstogo po novym materialam [La mort de Tolstoj, nouveaux documents], M., 1929. 